\title{
Natural Electromagnetic Energy Below the ELF Range
}

\author{
Wallace H. Campbell
}

\begin{abstract}
(February 23, 1960)
The transition of natural signals from sferics slow tails to geomagnetic micropulsations was observed between 2.0 and 0.2 cycles per second. Micropulsations with periods of 5 to 30 seconds have characteristics which closely relate to solar terrestrial disturbance phenomena. The low latitude diurnal amplitude variation has maximums at 0945 and 1000 l.m.t. Similar groups of oscillations appear in Alaska and California. Simultaneous pulsation of $\lambda 3914$ aurora and magnetic field micropulsations has been observed in Alaska.
\end{abstract}

\section{Introduction}

The purpose of this paper is to review some studies of the characteristics of natural electromagnetic fields which are encountered as measurements are made to frequencies lower than those dominated by the sferics slow tails. In particular, magnetic field oscillations with periods of 5 to 30 sec will be discussed. The greater part of this paper is a digest of experimental results which have been previously published. New developments in the relation of magnetic field micropulsations to the pulsating aurora will be reported.

Only the author's work will be discussed in this paper. However, it should be mentioned that recent comprehensive studies of the short period pulsating magnetic field have been made by Holmberg [1], ${ }^{2}$ Angenheister [2], Troyiçkaya [3], Kato and Watanabe [4], and Shand, Wright, and Duffus [5].

\section{Methods}

For the field strength observations in frequencies below 20 cps the antennas were large loops, $2 \mathrm{~m}$ in diameter with 21,586 turns [6]. The loop natural resonance was at approximately $150 \mathrm{cps}$. In operation the relatively flat system response was down by $3 \mathrm{db}$ at $0.4 \mathrm{cps}$ and $20 \mathrm{cps}$ for oscilloscope film recordings and at $0.04 \mathrm{cps}$ and $0.4 \mathrm{cps}$ for slow run Esterline Angus pen recorders. Wind velocity and WWV timing were also recorded on the film $[6,7]$. The maximum noise level was equivalent to 0.02 gamma and decreased with increasing frequency. Middle latitude observations were made at a southern California site $\left(33^{\circ} 21.5^{\prime} \mathrm{N}, 116^{\circ} 17^{\prime} \mathrm{W}\right)$ and high latitude experiments were carried out in Alaska $\left(64^{\circ} 42^{\prime} \mathrm{N}, 148^{\circ} 29.5^{\prime} \mathrm{W}\right)$.

1 Contribution from Geophysical Institute, University of Alaska; paper presented at Conference on the Propagation of ELF Radio Waves, Boulder, Colo., Jan. 25,1960

${ }_{2}$ Figures in brackets indicate the literature references at the end of this paper.

\section{Observations}

In California the transition of the dominate received natural signals from slow tail sferics to geomagnetic micropulsations was found to occur between 2.0 and $0.2 \mathrm{cps}[7]$. On a few rare occasions dispersive train oscillations with periods of approximately $1.5 \mathrm{cps}$ and amplitudes reaching 0.015 gamma were observed [6]. Sixty percent of the 4808 hours sampled between March and September 1958, showed sinusoidal type pulsations appearing in groups or packets of four or six oscillations with periods of 20 to 25 sec during the midday hours and falling to 5 to $8 \mathrm{sec}$ by midnight [6]. The periods did not seem to be amplitude dependent. In southern California the signals increased in amplitude at dawn, rose to a maximum of about one-quarter gamma about 0945 to 1000 l.m.t., then decreased to a slight minimum after $1200 \mathrm{hr}$, showed a secondary maximum at approximately $1400 \mathrm{hr}$, and faded away gradually in the late afternoon (fig. 1). From comparison with data of researchers $[2,3]$ in other parts of the world it is apparent that the diurnal pattern of micropulsations is a local mean time variation [7].

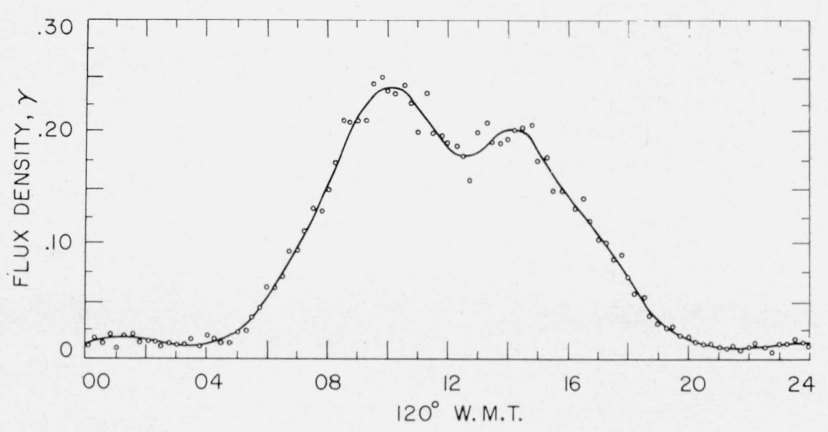

Figure 1. Average diurnal behavior of micropulsations in California from March through September 1958. 
Average daily amplitudes behave in a manner similar to other phenomena in the solar-terrestrial disturbance family. Good correlation may be obtained with magnetic $K$ and $A$ indices and disturbed $F$-layer conditions [7]. The 27 day periods of solar activity stands out on the records.

Several occasions a month there appeared "storms" of sudden increases in pulsation amplitude reaching an average of 1.4 gamma and followed for several hours by higher activity than would have been expected for the day [7]. The storm time variation showed a small secondary maximum at $65 \mathrm{~min}$. The occurrence distribution of the 19 storms studied had maximums at 0700 and 1645 u.t. On many occasions the micropulsation storms were coincident with sudden commencement magnetic storms.

At 10:51:30 \pm 30 u.t., August 1, 1958, a small group of micropulsations were initiated, lasting for approximately $4 \mathrm{~min}$ and attaining an amplitude of approximately 0.2 gamma. About 50 min later a second group of micropulsations commenced, rising gradually to a maximum of 0.3 gamma in 23 min then rapidly disappearing. Since local nighttime activity was rare in the low latitudes and previously accompanied by high magnetic $K$ indices, these oscillations were interpreted as a direct result of the high altitude (70 to $80 \mathrm{~km}$ [8]) nuclear explosions at Johnston Island. No micropulsations were observed on the August 12 Johnston Island explosion which was reported to occur at a lower elevation [8].

Twenty-three coincident active groups of micropulsations were observed in 6 days concurrent operation of California and Alaska stations [9]. Although the oscillation periods were similar, peak for peak correspondence was not evident. The diurnal pattern of micropulsations in the auroral zone is dominated by a post midnight maximum typical of the aurora itself [6]. Large nighttime activity in Alaska gave oscillations 10 to 20 times larger than
California. Daytime activities were similar at the two stations. In Alaska there seems to be a close relationship between the pulsating aurora and magnetic field micropulsations [10]. Using a lens, interference filter, photomultiplier, and appropriate amplifiers, observations were made of pulsations of the $\lambda 3914$ and $\lambda 5577$ auroral lines. Figure 2 shows typical records of corresponding magnetic field micropulsations and pulsating aurora. Figure 3 illustrates the average diurnal behavior of magnetic field micropulsations and pulsating aurora for occasions of joint operation in the month of December 1959. Figure 4 is an illustration of oscillations of the two phenomena in the predawn hours with periods of approximately 25 sec. The optical and magnetic measurements were made at sites separated by 30 miles.

\section{Concluding Remarks}

Magnetic field micropulsation, though certainly dependent upon solar terrestrial phenomena for their excitation, show many local diurnal features. There are strong indications that the ionosphere is intimately involved in the generation mechanism. It appears that the pulsating aurora is closely related if not identical to the micropulsation phenomena.

The low-latitude work was carried out at the Institute of Geophysics of the University of California and the continuing program in Alaska at the Geophysical Institute of the University of Alaska. The research has had the support of the Electronics Branch of the Office of Naval Research. The assistance of B. Nebel in California and of A. Belon, C. Deehr, M. Rees, and G. Romick in Alaska is gratefully acknowledged.

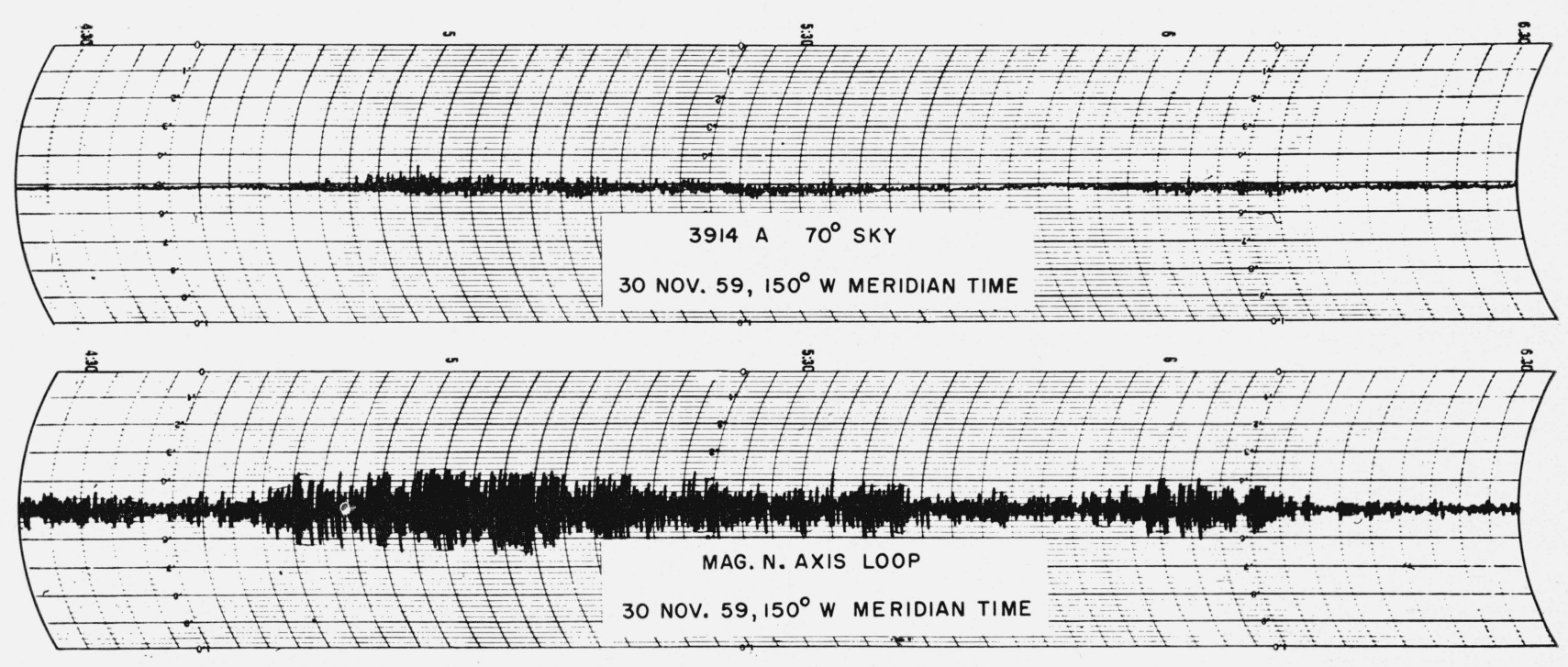

Figure 2. Example of magnetic field micropulsations and pulsation aurora data in Alaska. 


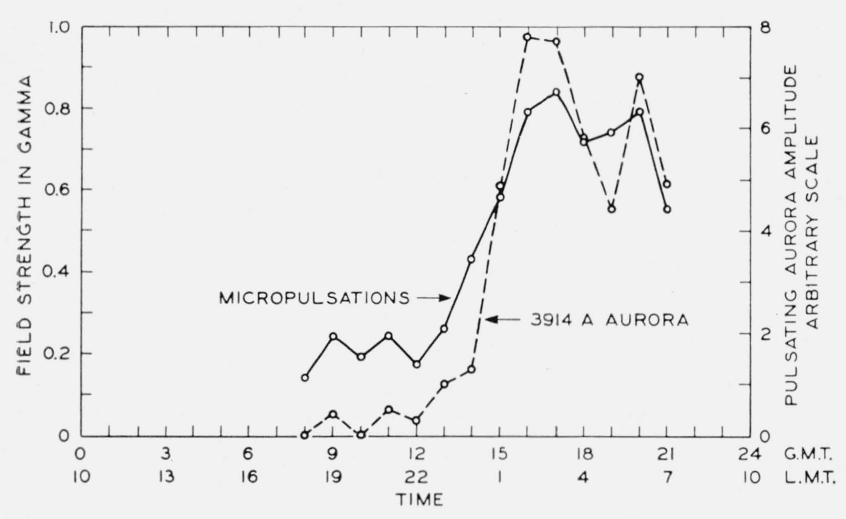

Figure 3. Average diurnal behavior of magnetic field micropulsation and pulsating aurora for the month of December 1959, in Alaska.

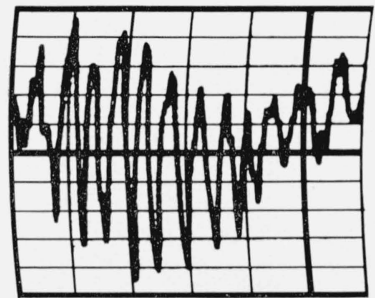

$\lambda 3914$

AURORA PULSATIONS

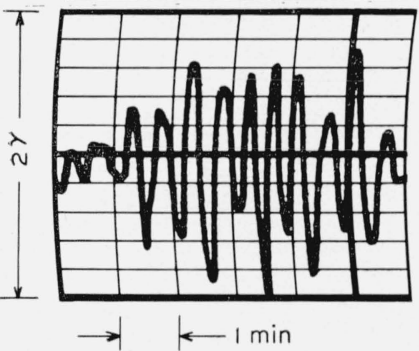

MAGNETIC FIELD MICROPULSATIONS

FIGURE 4. Corresponding pulsations of the aurora and the north magnetic field at stations separated by 30 miles near College, Alaska.

\section{References}

[1] E. R. R. Holmberg, Rapid periodic fluctuations in the geomagnetic field, I, Monthly Notices Roy. Astron. Soc., Geophys. Suppl. 6, 467 (1953).

[2] G. Angenheister, Registrierung erdmagnetischer pulsationen Gottingen, 1952/53, Gerlands Beitr. Geophys. 64, 108 (1954)

[3] V. A. Troyiçkaya, Earth currents, Priroda 5, 81 (1955)

4] Y. Kato and T. Watanabe, A. survey of observational knowledge of the geomagnetic pulsation, Sci. Rept. Tôhoku Imp. Univ., ser 5, Geophys. 8 (3), 157 (1957).

[5] J. A. Shand, C. S. Wright, and H. J. Duffus, A study of the distribution of geomagnetic micropulsations, Pacific Naval Lab. Rept. 15, D.R.B., Canada, pp. 1 to 29 (1959)

[6] W. H. Campbell, A study of micropulsations in the earth's magnetic field, Inst. Geophys., Univ. Calif. Los Angeles, Sci. Rept. 1, Nonr. 233 (47), 1 to 138 (1959).

[7] W. H. Campbell, Studies of magnetic field micropulsations with periods of 5 to 30 seconds, J. Geophys. Research 64, 1819 (1959).

[8] S. Matsushita, On artificial geomagnetic and ionospheric storms associated with high-altitude explosions, J. Geophys. Research 64, 1149 (1959).

[9] W. H. Campbell and B. Nebel, Micropulsation measurements in California and Alaska, Nature 184, 628 (1959).

[10] W. H. Campbell, Magnetic micropulsations and the pulsating aurora, J. Geophys. Research 65, 784 (1960).

(Paper 64D4-74) 